\title{
Visões do Estado sobre as Mulheres e o Plano Plurianual (PPA) 2016-2019
}

\author{
Janine Mello² \\ Ana Camila Ribeiro ${ }^{3}$ \\ Danusa Marques ${ }^{4}$
}

\section{INTRODUÇÃO ${ }^{5}$}

Alinhadas a trabalhos publicados anteriormente (Mello e Marques, 2019a; 2019b), retomamos a premissa de que a atuação estatal engloba e impacta, a partir de múltiplos instrumentos político-administrativos, distintas dimensóes da vida social e o modo com que certos pressupostos, crenças e valores são internalizados pelas estruturas governamentais pode contribuir para reforçar ou problematizar visóes sobre as mulheres enquanto destinatárias de direitos e deveres. Isso não significa que as interações entre Estado e mulheres estejam circunscritas a uma orientação unidimensional, dado o caráter inerentemente conflitivo e contraditório do Estado e a multiplicidade de mediaçóes ocorridas entre estruturas governamentais e mulheres enquanto grupo social mais amplo.

Em decorrência disso, argumentamos que a atuação do Estado em relação às mulheres apresenta variaçóes, devido à natureza complexa de suas açóes e a presença de atores dotados de distintos graus de poder e influência, o que permite que múltiplas visóes, por vezes contraditórias e paradoxais, coexistam no âmbito do próprio arcabouço estatal. Recuperamos, de trabalhos anteriores (Mello e Marques, 2019a; 2019b), a proposta de tipologia para a atuação estatal baseada em quatro visóes em relação às mulheres, conforme a ótica a partir da qual a presença feminina é entendida na elaboração de políticas públicas: i) visão reprodutiva (mulheres como mães/cuidadoras); ii) visão produtiva (mulheres enquanto mão de obra do trabalho remunerado); iii) a visão reativa (inclusão posterior das mulheres na execução da política); e iv) visão inclusiva (mulheres enquanto público-alvo prioritário). ${ }^{6}$

Vale ressaltar que essas categorias, embora tendam a ser tomadas como excludentes, não o são. A tipologia proposta está sujeita aos limites inerentes a toda esquematização voltada a apreender, mesmo que parcialmente, as dinâmicas complexas a partir das quais relaçóes sociais ocorrem e são estabelecidas. Ao propormos uma tipologia para as visōes assumidas pelo Estado - no que se refere às representaçôes sobre as mulheres enquanto referências para moldar a ação pública -, assumimos como ponto central a relevância de explicitar a natureza paradoxal da atuaçáo estatal e as múltiplas representaçôes que derivam da teia complexa que configura o arcabouço do Estado e suas interfaces com as demais instâncias e os atores sociais. Defendemos que, embora prevaleça uma visão reprodutiva sobre as mulheres, as dinâmicas de ação do Estado também partem de elementos vinculados a outros referenciais como a capacidade produtiva feminina, os esforços para incluir mulheres como público

1. DOI: http://dx.doi.org/10.38116/bapi28art6

2. Especialista em políticas públicas e gestão governamental (EPPGG) e diretora adjunta na Diretoria de Estudos e Políticas do Estado, das Instituições e da Democracia (Diest) do Ipea.E-mail: <janine.mello@ipea.gov.br>.

3. Pesquisadora do Programa de Pesquisa para o Desenvolvimento Nacional (PNPD) na Diest/lpea. E-mail: <ana.ribeiro@ipea.gov.br>.

4. Professora adjunta do Instituto de Ciência Política (Ipol) da Universidade de Brasília (UnB) e pesquisadora do Grupo de Pesquisa sobre Democracia e Desigualdades (Demodê).E-mail:<danusamarques@gmail.com>.

5. Uma versão ampliada deste texto foi publicada como Texto para Discussão em Mello, Ribeiro e Marques (2020).

6. Mais detalhes sobre cada uma das visões em Mello e Marques (2019a; 2019b). 
prioritário visando ao atendimento de demandas específicas, a implementação de medidas voltadas para assegurar a efetividade de políticas ou mesmo como resposta a pressóes e reivindicaçóes sociais por maior visibilidade e/ou atendimento do público feminino.

Argumentamos ainda que produtos governamentais como instrumentos de planejamento da ação estatal, materiais institucionais e documentos legais e operacionais correspondem a expressóes da atuação estatal. Assim, podem ser considerados uma opção analítica válida para explicitar sentidos, percepçóes e expectativas sobre o que é definido como objeto de intervenção política, assim como sobre o que é apontado como demanda pública e até mesmo quais indivíduos ou grupos devem ou não constituir o público-alvo preferencial de determinada ação (Gale, 1999; Maguire e Ball, 2015; Nicoll, 2000; Johnson, 2011). Mesmo nos casos em que não seja implementada efetivamente como a normativa pactuada, esse momento da definição de demandas por políticas expressa sentidos importantes nas possibilidades de ação negociadas no âmbito do Estado.

Representações atribuídas ao que constitui um dado problema e suas possíveis soluções resultam de interações imersas em ambientes conflitivos pautados por correlaçóes de força específicas (Yanow, 2015; Verloo e Lombardo, 2007; Schmidt, 2008; Shore e Wright, 2011; Bacchi, 1999). Por conseguinte, o que definimos como produto governamental também é forjado por meio dessas relaçóes e expressa, em algum sentido, representaçóes que prevaleceram em meio à disputa ideacional travada entre atores ou instituiçóes ao longo do processo de delimitação do escopo da ação governamental. Essas representaçóes - contidas, implícita ou explicitamente, em instrumentos de planejamento, planos de ação, previsóes orçamentárias, definição de diretrizes, estratégias e metas trazem em si ideias que, de alguma forma, transpuseram diferentes filtros e disputas ocorridas nas mais diversas instâncias decisórias (Offe, 1984; Lejano e Park, 2015; Ball, 1993; Foucault, 2008; Bourdieu, 2014).

Dito isso, fica evidente a pertinência de recorrer a enfoques teóricos que abordem o peso das ideias na configuração das políticas públicas e que reconhecem seu papel na produção de representaçóes sobre problemas sociais como norteadores da reflexão desenvolvida ao longo do texto em questão. Assumir a existência de distintas visóes estatais sobre um dado tema e a possibilidade de depreender elementos subjacentes a essas representaçóes abre espaço para a discussão sobre o impacto das ideias na conformação assumida pelas políticas públicas em detrimento de outros arranjos, escopos e estratégias possíveis.

Essas considerações trazem para o cerne da análise questões sobre o que essas visões representam, quais elementos as constituem ou, mais objetivamente, como afetam a produção de políticas públicas, sua implementação e seus impactos produzidos sobre populaçóes e territórios. Indo adiante, centrar o foco nesse aspecto nos coloca diante de questionamentos sobre os sentidos de entender essas especificidades e a relevância de explicitar essas representaçóes para a análise de políticas públicas.

Propomos que as visões estatais sobre as mulheres são compostas por ideias que atribuem sentidos específicos a questóes associadas à pauta de demandas e reivindicaçóes femininas. Na prática, a caracterização do que é entendido como "demanda feminina" nas políticas públicas requer que um conjunto específico de aspectos seja eleito como o mais pertinente ou adequado para orientar a ação estatal em detrimento de outras possibilidades. Os efeitos da delimitação dos elementos interpretativos usados para abordar essas questóes impactariam, de alguma maneira, o escopo das estratégias contidas em diferentes instrumentos de planejamento da ação governamental. 
Partindo desse entendimento, o objetivo central do texto é compreender como e quais visóes do Estado sobre as mulheres permeiam o conteúdo dos objetivos, metas e iniciativas propostas no âmbito do Plano Plurianual (PPA) 2016-2019. Nesse sentido, o caráter generalista do PPA e sua diversidade temática permitiriam identificar compromissos e orientaçóes de natureza mais abrangente e, a priori, captar representaçóes sobre aquilo que constitui as principais preocupaçóes governamentais em matéria de produção de políticas.

Isso, obviamente, não significa afirmar que não existam variações entre o que está previsto no PPA e o que efetivamente ocorre no âmbito da atuação governamental e menos ainda que ideias e sentidos que o compóem correspondam a referenciais internalizados e compartilhados de maneira homogênea ou integral pelo conjunto da administração pública. Nosso argumento, entretanto, é de que o PPA, para os fins propostos na análise, poderia fornecer indícios sobre visóes que prevaleceram após uma sequência de ritos e procedimentos burocráticos repleta de disputas, de maior ou menor grau e intensidade, sobre aspectos que deveriam ou não compor sua versão final enquanto instrumento de planejamento da ação governamental de curto e médio prazo.

Para isso, foram analisadas metas, iniciativas e objetivos do PPA 2016-2019 adotando o método de text mining, ${ }^{7}$ em que para cada categoria proposta na tipologia foi atribuído um conjunto de termos relacionados a aspectos elencados como centrais para compreender as visóes do Estado sobre as mulheres. A essa etapa se seguiu a análise qualitativa de cada um dos casos e uma classificação em categorias selecionadas. A expectativa é de que, a partir disso, seja possível identificar visóes hegemônicas no âmbito das açôes previstas no PPA, assim como aproximaçóes e distanciamentos existentes entre essas categorias no que se refere a aspectos como distribuição entre órgãos, áreas temáticas e viés de atendimento às mulheres.

\section{DELINEAMENTOS METODOLÓGICOS}

Foram considerados todos os 54 programas temáticos, 303 objetivos e 1.132 metas/iniciativas que compuseram o PPA 2016-2019 (Brasil, 2015). Considerado o teor atribuído a essas categorias, é razoável supor que a análise desses elementos forneceria, potencialmente, indícios sobre como ocorre a incorporação das mulheres no escopo dessas políticas e quais visóes estatais emergem dessas estratégias. No intuito de verificar a pertinência dessas suposiçóes, a análise foi dividida em duas etapas.

\subsection{Etapa 1: identificação dos termos relacionados às visões estatais sobre as mulheres}

Para permitir a análise dos campos previstos no PPA a partir das diferentes representaçóes associadas às visóes estatais foi realizada a análise textual dos seguintes campos: objetivos, metas e iniciativas. Isso permitiu a identificação de termos e expressões que pudessem indicar, direta ou indiretamente, mulheres enquanto público afetado pela ação. Também implica assumir que, mesmo que uma ação não tenha mulheres como público-alvo específico, elas podem ser afetadas, de maneira positiva ou não, pela execução de uma série de políticas e ações.

Para tanto, utilizou-se o procedimento de text mining para localizar termos associados às diferentes visóes estatais de acordo com pressupostos e premissas contidos em cada uma delas. No caso da visão reprodutiva, julgamos pertinente listar termos associados à maternidade, à infância

7. Text mining ou mineração de dados textuais é um procedimento que permite a análise textual de dados conforme a presença ou ausência de termos predefinidos. No caso dessa análise foi utilizado um script específico desenvolvido pelas autoras a partir do software estatístico R. Mais informações em Feldman e Sanger (2006). 
e ao cuidado. Já na visão produtiva foram selecionados termos ligados ao mercado de trabalho como produtora, trabalhadora, empreendedora, por exemplo. No caso da visão inclusiva foram incluídos termos como discriminação, violência, sexismo, feminicídio, entre outros. E foram incluídos, ainda, na análise, termos mais genéricos que poderiam estar associados a qualquer uma das visóes, como mulher, beneficiária, feminino e gênero. É importante ressaltar que, apesar da tipologia proposta conter quatro visóes estatais, foram consideradas apenas três delas em função da natureza do PPA enquanto instrumento de planejamento de açôes. Não é possível, nesse sentido, identificar casos vinculados à visão reativa nos campos analisados, razão pela qual estão ausentes da análise, apesar da possibilidade de que essas ações sejam passíveis de modificação ao longo de sua implementação. As categorias e termos associados a cada uma das visóes estão descritos no quadro $1 .{ }^{8}$

QUADRO 1

Tipologia segundo visões estatais e termos correlatos ${ }^{1}$

\begin{tabular}{|l|l|}
\hline \multicolumn{1}{|c|}{ Categorias } & \multicolumn{1}{c|}{ Termos associados } \\
\hline Geral ${ }^{2}$ & Mulher, feminina, gênero, sexo, sexual, menina \\
\hline Visão inclusiva & $\begin{array}{l}\text { Feminicídio, discriminação, sexismo, LGBT, lésbica, transexual, homossexualidade, transgênero, sexualidade, violência doméstica, } \\
\text { violência contra a mulher, assédio sexual, idosa, negra }\end{array}$ \\
\hline Visão produtiva & Trabalhadora, produtora, empreendedora, empresária, assalariada, desempregada, empregada, doméstica \\
\hline Visão reprodutiva & Mãe, materno, maternidade, gestante, lactante, cuidado, infantil, criança, infância, gravidez, grávida, amamentação, lactação \\
\hline
\end{tabular}

Elaboração das autoras.

Notas: ${ }^{1}$ Foram consideradas as inflexões de gênero e o singular e plural de todos os termos.

${ }^{2}$ Os termos classificados como geral podem aparecer associados a qualquer uma das visões listadas no quadro, por isso possuem uma categoria própria.

\subsection{Etapa 2: qualificação da ação estatal em relação às mulheres}

Para aprimorar o recorte baseado nos termos encontrados, foram atribuídas qualitativamente outras variáveis a cada um dos objetivos, metas e iniciativas que permitissem compreender se e como o atendimento de mulheres estava previsto na descrição dos campos textuais analisados. Essa opção mostrou-se válida porque a associação direta entre os casos e as categorias previstas na tipologia de visões estatais sobre as mulheres não seria suficiente para indicar as nuances contidas nos diferentes casos analisados. Para mitigar essa lacuna, as variáveis agregadas à análise foram divididas em tema ou macro-objetivo, viés de atendimento das mulheres e público-alvo da ação, detalhadas no quadro 2.

8. Vale ressaltar que a presença de termos como família, criança ou cuidado não é suficiente para indicar a existência de um componente de gênero no escopo de determinada meta ou iniciativa, por exemplo, nem mesmo se mulheres podem vir a ser, direta ou indiretamente, afetadas/impactadas por essas ações. Em função disso, foi necessário analisar cada um dos casos captados pelo algoritmo para confirmar de que forma mulheres seriam afetadas por essas ações. 
QUADRO 2

Variáveis agregadas à análise, sua descrição e categorias

\begin{tabular}{|c|c|c|}
\hline Variáveis & Descrição & Categorias \\
\hline Viés de atendimento & $\begin{array}{l}\text { - Refere-se à forma com que as } \\
\text { mulheres são incorporadas na ação e } \\
\text { consequentemente como são atendidas } \\
\text { por elas. Essas situações podem variar } \\
\text { desde o atendimento de mulheres } \\
\text { como parte do conjunto da população, } \\
\text { passando por casos em que elas são } \\
\text { atendidas enquanto mães de crianças e } \\
\text { adolescentes, ou como membro de um } \\
\text { núcleo familiar, até os casos em que as } \\
\text { mulheres são apontadas como principal } \\
\text { público da ação } \\
\text { - Relação com a incorporação das } \\
\text { mulheres à ação }\end{array}$ & $\begin{array}{l}\text { - Universal ou difuso: são atendidas por pertencerem à população como } \\
\text { um todo sem que existam critérios explícitos de inclusão de determinadas } \\
\text { - Igualdade de gênero: demandas associadas às mulheres constituem } \\
\text { o escopo majoritário da ação e existe preocupação com a redução de } \\
\text { desigualdades entre homens e mulheres } \\
\text { - Cuidado: são incorporadas à ação a partir de papéis associados } \\
\text { ao cuidado orientados para atender crianças, idosos, portadores de } \\
\text { deficiência etc. } \\
\text { - Arranjo familiar: incorpora-se à ação como parte de um núcleo familiar. } \\
\text { A família constitui a unidade de atendimento prevista } \\
\text { - Principais beneficiárias das políticas: são as principais beneficiárias da } \\
\text { ação por razões administrativas/legais (titularidade do Programa Bolsa } \\
\text { Família - PBF, por exemplo) ou por constituírem a maioria do público } \\
\text { beneficiado mesmo sem haver previsão específica }\end{array}$ \\
\hline Tema ou macro-objetivo & $\begin{array}{l}\text { - Grande área à qual a ação pertence no } \\
\text { âmbito das políticas públicas setoriais } \\
\text { - Relação com a finalidade da ação }\end{array}$ & $\begin{array}{l}\text { - Acesso a serviços: ações que visam ampliar o acesso a serviços básicos } \\
\text { como saúde e educação } \\
\text { - Inclusão social e transferência de renda: ações ligadas a programas como } \\
\text { PBF, Benefício de Prestação Continuada (BPC) e políticas socioassistenciais } \\
\text { - Inclusão produtiva: ações voltadas para a ampliação de oportunidades } \\
\text { laborais e de geração de renda } \\
\text { - Cidadania: ações referentes à promoção de direitos humanos, pautas } \\
\text { identitárias e de reconhecimento } \\
\text { - Outros: ações que não enquadradas nas anteriores }\end{array}$ \\
\hline $\begin{array}{l}\text { Público-alvo } \\
\text { (grandes grupos)' }^{1}\end{array}$ & $\begin{array}{l}\text { - Público ao qual se destina a ação } \\
\text { - Relação com direcionamento da ação }\end{array}$ & $\begin{array}{l}\text { - População em geral } \\
\text { - População em situação de vulnerabilidade: população de baixa } \\
\text { renda, beneficiários do PBF e Cadastro Único ou em situação de } \\
\text { violação de direitos } \\
\text { - Outros segmentos ligados ao cuidado: idosos e pessoas com } \\
\text { deficiência (PCD) } \\
\text { - Crianças e adolescentes } \\
\text { - Mulheres } \\
\text { - Minorias e grupos difusos: referência a vários grupos populacionais } \\
\text { incluídos na mesma ação. Casos em que uma só medida inclui diversos } \\
\text { públicos como população negra, mulheres, população LGBT, juventude e } \\
\text { meio rural etc. } \\
\text { - Grupos populacionais específicos: ação especifica quem vai receber a } \\
\text { açãa entre grupos como povos e comunidades tradicionais, agricultores } \\
\text { familiares, assentados da reforma agrária }\end{array}$ \\
\hline
\end{tabular}

Elaboração das autoras.

Nota: ${ }^{1}$ Os diferentes públicos verificados totalizaram dezessete tipos que foram, posteriormente, agregados segundo grandes grupos conforme as categorias apresentadas.

\section{DISCUSSÃO DOS RESULTADOS}

De maneira geral, as mençôes às mulheres aparecem atreladas a dois componentes: i) áreas temáticas de igualdade de gênero e políticas de desenvolvimento social; e ii) sempre em conjunto com outros públicos específicos. Julgamos relevante entender de que forma essas representaçôes ou expectativas 
enunciadas nas seçóes mais abrangentes do PPA dialogam com o detalhamento descrito em metas, iniciativas e objetivos apresentados. Por essa razão, recorreremos ao conteúdo textual desses campos como expressóes mais significativas de possíveis representaçóes associadas às mulheres no âmbito das açóes previstas no PPA.'

Retomando a pergunta inicial sobre como diferentes visóes do Estado sobre as mulheres permeiam o conteúdo de objetivos, metas e iniciativas propostos no âmbito do PPA 2016-2019, os resultados indicaram a prevalência, entre objetivos e iniciativas/metas, de açóes caracterizadas pelos seguintes elementos:

- concentração em poucos órgãos da estrutura federal, onze dos então ministérios vigentes à época, com alta prevalência em dois deles: Presidência da República e o então Ministério dos Direitos Humanos;

- cidadania prevalece como principal tema das açôes que estiveram associadas de alguma forma às mulheres, conforme a metodologia adotada na análise;

- o atendimento às mulheres ocorreu predominantemente a partir do viés de igualdade de gênero, o que poderia ser lido como indicativo de esforços voltados para a agenda de promoção da igualdade de gênero - embora a segunda posição ainda seja ocupada por estratégias baseadas na lógica do cuidado em que as mulheres são incorporadas à ação a partir da sua responsabilização por setores populacionais com algum grau de dependência; e

- forte presença de mulheres, enquanto grupo mais amplo, como público beneficiário acompanhado da incidência de mulheres pertencentes a grupos populacionais específicos como destinatárias de outro conjunto de açóes, apontando a coexistência entre estratégias de caráter mais abrangente na definição do foco de suas ações e outras orientadas para atender mulheres a partir de especificidades que as caracterizem.

Considerando as articulaçóes existentes entre as variáveis contempladas, mulheres, em sua noção mais ampla, prevalecem como público naquelas açôes que adotam viés de atendimento atrelado à promoçáo da igualdade de gênero e em temas concernentes à agenda de cidadania.

Em relação aos vieses, a igualdade de gênero aparece associada a pautas de cidadania, inclusão produtiva e acesso a serviços, o que pode ser entendido como um aspecto positivo se levarmos em conta a diversidade da pauta e o potencial atendimento multidimensional de demandas associadas às mulheres. No entanto, apesar de heterogêneas, essas açóes estão predominantemente concentradas em órgãos específicos. A dimensão de transversalidade inerente a temas dessa natureza requer muitas vezes uma atuação que extrapola a governança de um único órgão sobre um rol bastante diversificado de assuntos. Ações que apresentam viés de igualdade de gênero, por exemplo, estiveram fortemente sob a responsabilidade da Presidência da República que, como já mencionado, abrigou durante grande parte desse período a Secretaria de Políticas para as Mulheres, a Secretaria de Políticas para Igualdade Racial e a Secretaria de Agricultura Familiar.

É possível argumentar que as ações do PPA captadas na análise indicam uma preocupação de caráter mais geral com as mulheres (representada pela prevalência dos temas de cidadania e viés de igualdade de gênero). Quando termos associados às diferentes visóes sobre as mulheres aparecem, estão distribuídos em objetivos e/ou iniciativas/metas ligados majoritariamente a temas de cidadania e ao viés de atendimento de igualdade de gênero. O que, de maneira preliminar, poderia indicar

9. Todos os resultados estão detalhados e descritos em Mello, Ribeiro e Marques (2020). 
adesão entre os aspectos verificados nas seçôes mais gerais do PPA e o detalhamento contido na descrição dos objetivos e iniciativas/metas indicados para determinado período.

Merece destaque ainda a constatação de que a inserção das mulheres em várias açóes previstas no PPA ocorre a partir de situaçóes ou clivagens que caracterizam especificidades vivenciadas por alguns grupos em particular. Em certo sentido, isso pode ser lido como potencial incentivo à transversalidade, ao mesmo tempo que, sem a devida articulação e integração setorial, esse aspecto pode contribuir para ampliar o caráter fragmentado e setorializado da oferta de políticas direcionadas às mulheres.

Apesar da concentração em poucos órgãos, quando consideramos as representaçôes associadas às mulheres que emergem da análise dos objetivos, metas e iniciativas dispostos no PPA, verificamos um cenário de coexistência entre visóes inclusivas (igualdade de gênero), reprodutivas (foco na dimensão do cuidado) e produtivas (mão de obra do trabalho remunerado) - esta última, principalmente, associada a especificidades étnicas, territoriais ou ligadas à natureza da atividade econômica.

Diferentemente do que poderíamos supor a partir da literatura existente sobre as formas de inclusão feminina nas políticas públicas, a visão reprodutiva não prevalece numericamente sobre as demais. Apesar de o cuidado e as açóes direcionadas a crianças e adolescentes ocuparem lugar significativo nas propostas indicadas no PPA 2016-2019 - em especial se considerados o porte orçamentário e a abrangência desses programas -, foi possível verificar a existência de outras visóes sobre as mulheres no escopo do PPA 2016-2019: seja como esforço para maior inserção produtiva de mulheres pertencentes a grupos populacionais específicos, reconhecendo a sobreposição de clivagens sociais como relevantes nas dinâmicas de exclusão de mulheres enquanto público das políticas públicas; seja, ainda, a partir de esforços, mesmo que concentrados em poucos órgãos, de assumir compromissos e definir diretrizes orientadas para a construção de estratégias transversais de promoção da igualdade de gênero.

\section{CONSIDERAÇÕES FINAIS}

Ao longo do texto, propusemos que as visões estatais sobre as mulheres são configuradas por ideias capazes de atribuir sentido a questóes entendidas como demandas e reivindicaçóes femininas. $\mathrm{Na}$ prática, a caracterização do que constituiria esse rol de demandas nas políticas públicas requer que um conjunto específico de aspectos seja eleito como o mais pertinente ou adequado para orientar a ação estatal em detrimento de outras possibilidades. Assumimos ainda que os efeitos da delimitação dos elementos interpretativos mobilizados para abordar essas questóes exercem potencial impacto sobre o escopo das diferentes estratégias que constituem a atuação governamental.

Nesse intuito foram articuladas noçōes decorrentes dos debates sobre o papel exercido pelas ideias na produção de políticas públicas; sobre o uso de policy texts como instrumento analítico pertinente para compreender a construção dos públicos-alvo das açóes governamentais e suas dinâmicas de inclusão e exclusão; assim como as diferentes representaçóes associadas às mulheres em políticas que gerem efeito, direto ou indireto, sobre o público feminino.

Vale ressaltar que a análise limitou-se à observação das visões estatais sobre as mulheres a partir de um produto governamental específico, o PPA 2016-2019. ${ }^{10} \mathrm{O}$ objetivo era explicitar representaçóes dispostas no conteúdo textual das açóes que o compóem, sem, entretanto, avançar na discussão sobre

10. Uma possibilidade de agenda futura de pesquisa seria fazer a mesma análise para os demais PPAs e avaliar o comportamento desses resultados ao longo do tempo. 
a natureza e/ou intensidade das repercussões decorrentes da prevalência dessas noçóes em detrimento de outras possíveis na operacionalização dessas ações sobre as mulheres.

\section{REFERÊNCIAS}

BACCHI, C. L. Women, policy and politics: the construction of policy problems. London: Sage, 1999.

BALL, S. J. What is policy? Texts, trajectories and toolboxes. Discourse: Studies in the Cultural Politics of Education, v. 13, n. 2, p. 10-17, 1993.

- What is policy? 21 years later: reflections on the possibilities of policy research. Discourse: Studies in the Cultural Politics of Education, v. 36, n. 3, p. 306-313, 2015.

BOURDIEU, P. Sobre o Estado. Companhia das Letras: Rio de Janeiro, 2014.

BRASIL. Ministério do Planejamento, Orçamento e Gestão. Plano plurianual 2016-2019: desenvolvimento, produtividade e inclusão social. Brasília: MP, 2015.

FELDMAN, R.; SANGER, J. The text mining handbook: advanced approaches in analyzing unstructured data. 1. ed. Cambridge: Cambridge University Press, 2006.

FOUCAULT, M. Microfísica do poder. Rio de Janeiro: Graal, 2008.

GALE, T. Policy trajectories: treading the discursive path of policy analysis. Discourse: Studies in the Cultural Politics of Education, v. 20, n. 3, p. 393-407, 1999.

JOHNSON, D. C. Critical discourse analysis and the ethnography of language policy. Critical Discourse Studies, v. 8, n. 4, p. 267-279, 2011.

LEJANO, R. P.; PARK, S. J. The autopoietic text. In: FISCHER, F. et al. (Ed.). Handbook of critical policy studies. Cheltenham: Edward Elgar, 2015.

MAGUIRE, M.; BALL, S.; BRAUN, A. Behaviour, classroom management and student 'control': enacting policy in the English secondary school. International Studies in Sociology of Education, v. 20, n. 2, p. 153-170, 2010.

MELLO, J.; MARQUES, D. Elementos para uma tipologia de gênero da atuação estatal: visões do Estado sobre as mulheres e políticas públicas no Brasil. Brasília: Ipea, 2019a. p. 7. (Texto para Discussão, n. 2441).

. Dos estereótipos à cidadania: sobre mulheres, Estado e políticas públicas. In: PIRES, R. R. C. (Org.). Implementando desigualdades: reprodução de desigualdades na implementação de políticas públicas. Rio de Janeiro: Ipea, 2019b.

MEllo, J.; RIBEIRO, A. C.; MARQUES, D. Policy texts e o papel das ideias nas políticas públicas: visóes estatais sobre as mulheres no PPA 2016-2019. Brasília: Ipea, 2020. (Texto para Discussão, n. 2553). Disponível em: <https://www.ipea.gov.br/portal/index.php?option=com_ content\&view=article $\&$ id $=35470 \&$ Itemid $=448>$. 
NICOLL, K. Lifelong learning as metaphor: researching policy in the education of adults. In: ADULT EDUCATION RESEARCH CONFERENCE, 2000, Vancouver, Canada. Anais... Vancouver: Aerc, 2000.

OFFE, C. Problemas estruturais do Estado capitalista. Rio de Janeiro: Tempo Brasileiro, 1984.

SCHMIDT, V. A. Discursive institutionalism: the explanatory power of ideas and discourse. Annual Review of Political Science, v. 11, p. 303-326, 2008.

SHORE, C.; WRIGHT, S.; PERÓ, D. (Ed.). Policy worlds: anthropology and the analisis of contemporary power. New York: Berghahn, 2011.

VERLOO, M.; LOMBARDO, E. Contested gender equality and policy variety in Europe: introducing a critical frame analysis approach. In: VERLOO, M. (Ed.). Multiple meanings of gender equality: a critical frame analysis of gender policies in Europe. Budapest: CEU, 2007.

YANOW, D. Making sense of policy practices: interpretation and meaning. Cheltenham: Edward Elgar, 2015. 
